Revista de Economia Política, vol. 28, $n^{\circ} 1$ (109), pp. 155-165, janeiro-março/2007

\title{
Respostas a uma crítica marxista às perspectivas retórica e pragmática em economia
}

\author{
DANILO ARAÚJO FERNANDES, \\ PAULO GALA \\ JOSÉ MÁRCIO REGO*
}

\begin{abstract}
Answers to a marxist critic of the rhetorical and pragmatic perspectives in economics. Based on recent discussions regarding the rhetorical perspective in economics, this paper presents an interpretation of the philosophical approach of $\mathrm{Ha}-$ bermas which attempts to rescue the so called 'modern spirit', forgotten in the annals of the 19th century, similar to that presented by Marshall Berman in 1982. Following the reconstructive approach of Habermas's project of modernity, we attempt to show how a 'rhetorical approach' could be applied in the field of economics, and yet still be clearly modern by taking into account intersubjectivities, given the expanded sphere of human communication (as defended in the theory of communicative action of Habermas). In this sense, we will seek to demonstrate the philosophical limits of the anti-rhetorical critiques of, for example, Paulani (1996, $2003,2005,2006)$, which seem to underestimate the linguistic and intersubjective aspect of Habermas's philosophical project that can also be found in McCloskey's methodological approach.

Key-words: Rhetoric project, modernity, linguistic turn and intersubjectivity.

JEL Classification: B41.
\end{abstract}

\section{AVENTURAS E DESVENTURAS DE UMA CRÍTICA DAS PERSPECTIVAS RETÓRICA E PRAGMÁTICA EM ECONOMIA}

Numa das mais difundidas, criativas e insistentes críticas ao projeto retórico de McCloskey feitas dentro do debate metodológico em economia no Brasil, a

\footnotetext{
"Respectivamente, Professor da Universidade Federal do Pará - UFPA, e-mail: , Professor da Fundação Getúlio Vargas de São Paulo - FGV/SP, e-mail: pgala@uol.com.br; Professor da Fundação Getúlio Vargas de São Paulo - FGV/PS, e-mail: jm-rego@uol.com.br.
} 
professora Leda Paulani se utiliza, como principal inspiração, de uma tradição do pensamento crítico literário brasileiro - que vem de Antônio Cândido e chega a Roberto Schwarz e ao filósofo Paulo Eduardo Arantes - com o objetivo de tentar dar um sentido histórico e materialista à obra metodológica de McCloskey. A diferença, no entanto, entre a crítica literária de Schwarz e a suposta avaliação metodológica de Paulani sobre McCloskey está em que, enquanto Schwarz (1977) pretende em seu texto Idéias fora do lugar, demonstrar de que forma os ideais liberalizantes do século XIX desembarcam em terras e ambiente escravocrata brasileiro através do estudo da literatura romântica de José de Alencar e Machado de Assis, Paulani pretende inicialmente demonstrar a falta de lugar filosófico para as idéias metodológicas de McCloskey. Em seu ensaio de 1996, Idéias sem Lugar: sobre a retórica da economia de McCloskey, Paulani inicia seu ataque frontal à obra de McCloskey com clara inspiração no título do famoso ensaio de Roberto Schwarz, mas, como ela mesma alude depois em sua autocrítica, sem utilizá-lo no sentido original ou mesmo em qualquer perspectiva histórica ou materialista (ver Paulani, 2005, p. 21-22).

Em seu último texto, Retórica e Neoliberalismo: o capítulo brasileiro, e em seu mais recente livro Modernidade e Discurso econômico, Paulani pretende recuperar o tempo perdido e tenta enquadrar a obra de McCloskey em uma perspectiva histórica, que atribui à retórica um papel e sentido determinado ideologicamente em relação ao contexto de desenvolvimento do capitalismo e do neoliberalismo no final da segunda metade do século XX. Na introdução deste seu último livro sobre as relações entre modernidade e discurso econômico, Paulani pretende deixar claro, por outro lado, também, sua preocupação em explicitar quais os principais motivos que a haviam levado a se preocupar com o tema da modernidade e seus desdobramentos sobre o debate metodológico em economia. Num movimento intelectual (a nosso ver bastante esclarecedor) faz uma retrospectiva das repercussões que a perspectiva retórica de McCLoskey havia conseguido alcançar perante a platéia de economistas heterodoxos no Brasil.

$\mathrm{Na}$ visão de Paulani (2005, p. 20), o projeto da retórica na economia (pelo menos na versão McCloskey) foi considerado inicialmente fecundo do ponto de vista da crítica heterodoxa, e da explicitação da pobreza metodológica do mainstream em economia, levando Paulani a se intrigar, e a procurar melhor destrinchar os caminhos metodológicos que poderiam levá-la a uma melhor compreensão da perspectiva retórica de McCloskey. Justiça seja feita, a recíproca também é verdadeira. Pelo menos no Brasil, debater com Paulani, foi algo importante para nós (simpatizantes da perspectiva retórica de McCloskey) bem como, com certeza, para muitos adeptos ou simpatizantes da utilização dos métodos e técnicas de análise retórica para avaliação de textos econômicos: Bianchi (2003), Fernandez e Pessali (2003), Anuatti (2003), Gala (2003), entre outros. Paulani, não obstante ter se colocado desde o início de modo bastante crítico com relação aos adeptos mais próximos à perspectiva original de McCloskey, não deixa de concordar em nenhum momento, "com a importância e mesmo a necessidade das 
análises retóricas dos textos produzidos pela assim chamada ciência econômica" (Paulani, 2005, p. 189).

Neste sentido, referindo-se mais especificamente à sua polêmica com Rego (1996) sobre o lugar filosófico da retórica de McCloskey — assim como aos desdobramentos posteriores destes debates — registra Paulani:

"Minha investigação sobre a filiação epistemológica de McCloskey desembocou num resultado interessante. Olhando as coisas mais de perto, sua posição não se encaixava bem em lugar nenhum: nem no pósmodernismo, qualquer que fosse sua versão, nem no anarquismo metodológico de Feyerabend, nem na Sprachethik de Habermas, menos ainda na Teoria Crítica inaugurada por Marx. Isto posto, o título do meu artigo veio-me quase naturalmente: 'Idéias sem lugar: sobre a retórica da economia de McCloskey'. José Marcio Rego (1996) sinceramente simpático à pregação em favor da retórica, criticara-me por não ter contraposto as idéias de McCloskey ao neopragmatismo de Rorty, concluindo derivar daí o resultado inglório de minha busca por um 'lugar' onde ancorar suas idéias. Concedendo-lhe em parte razão, pois de fato não 'testara' essa hipótese, e vendo-me obrigada a responder suas críticas, não só fui estudar Rorty como adentrei a leitura de textos que se alinham com a melhor tradição daquilo que se poderia chamar 'crítica materialista' (...) E foi graças a esse périplo e ao amparo que encontrei nos trabalhos de Arantes que me deparei com uma obviedade que a mim ainda não se havia apresentado por inteiro e/ou com a clareza necessária (graças a simploriedade filosófica com que eu até então vinha absorvendo, de um lado, a leitura dialética de Marx e, de outro, as discussões epistemológicas envolvendo a ciência econômica): que a história das idéias não se determina por si mesma; a produção das idéias determinase inescapavelmente pelo lugar histórico de sua germinação, pelas circunstâncias temporais e pelas contingências locais da vida material onde são geradas, donde sua inevitável transformação ideológica quando deslocadas de seu lugar de origem" (Paulani, 2005, p. 23).

Sendo assim, eis que voltamos ao nosso objetivo inicial, qual seja: demonstrar os possíveis problemas filosóficos desta crítica contra a perspectiva retórica e pragmática que Paulani resolve levar a cabo por uma perspectiva materialista. Problemas estes que, a nosso ver, acabaram por direcioná-la rumo a um movimento intelectual e filosófico que peca fundamentalmente por tentar ofuscar as possibilidades emancipatórias e críticas presentes no cerne da proposta metodológica de McCloskey. Um movimento filosófico que, no limite, se mostra excessivamente simplificador; supervalorizando uma espécie de "correlação espúria", que busca associar historicamente o surgimento da abordagem retórica de McCloskey ao advento do neoliberalismo. 


\section{HABERMAS E O “DISCURSO FILOSÓFICO DA MODERNIDADE”: UMA CRÍTICA À INTERPRETAÇÃO SUBJETIVISTA DE PAULANI}

Com o objetivo geral de tentar identificar o "pecado original" de Paulani e os problemas em termos de sua interpretação filosófica básica sobre alguns dos principais autores que tem influenciado o debate filosófico contemporâneo, concentraremos esta parte do trabalho em uma breve avaliação crítica em relação à interpretação que Paulani parece fazer do Discurso Fiolosófico da Modernidade de Jürgen Habermas. ${ }^{1}$ Se fizermos uma avaliação cuidadosa da obra de Habermas, poderemos verificar a interpretação problemática que Paulani faz da visão que Habermas tem da perspectiva filosófica de Hegel, o que, a nosso ver, se reflete em sua dificuldade em apreender corretamente a filosofia crítica de Habermas em sua totalidade. Em seu último livro, Modernidade e Discurso Econômico, Paulani nos apresenta Hegel, a partir de Habermas (2000), como se o debate sobre o discurso filosófico da modernidade de Habermas se encerrasse, e não se iniciasse a partir de Hegel. Paulani, neste sentido, utiliza-se da interpretação de Habermas sobre Hegel, sem procurar contextualizar o significado desta interpretação dentro da proposta filosófica geral de Habermas - a qual, a nosso ver, busca colocar a filosofia de Hegel como grande precursora e embrião de toda a autocompreensão contemporânea do discurso filosófico da modernidade. Hegel, neste sentido, para Habermas, teria tido o mérito de nos ter permitido melhor compreender historicamente os limites de uma concepção de racionalidade voltada subjetivamente para a tradição da filosofia do entendimento de Kant.

Habermas, no entanto, em nenhum momento parece pressupor (como parece querer Paulani) que Hegel seja a última palavra sobre a correta compreensão do sentido da crítica da modernidade em sua versão subjetivista e de matriz kantiana. Muito pelo contrário. A decisão de encerrar a discussão sobre os limites do discurso filosófico da modernidade, assim como do conceito de modernidade, em Hegel, e daí partir diretamente para os seus prolongamentos a partir de Marx e Arantes (1996), foi uma opção de Paulani, não de Habermas. Uma opção que deixa transparecer que a autora só se interessou por esta parte da "estória". Como se o livro de Habermas, assim como toda a história da filosofia contemporânea se iniciasse e terminasse em Hegel e Marx. Decisão esta que, a nosso ver, trará sérias limitações para as conclusões que a autora tentará inferir em termos de sua crítica em relação à abordagem retórica de McCloskey.

Ao contrário do que nos parece propor Paulani (1996, 2005), na visão de Habermas, Hegel teria buscado em sua filosofia reunificar o projeto filosófico iluminista da modernidade que havia se dilacerado historicamente e conceitualmente em várias visões de mundo desde Kant; mas que, para Habermas, mesmo depois do

\footnotetext{
${ }^{1}$ Para uma primeira avaliação da polêmica sobre a interpretação que Paulani parece fazer da obra de Habermas, ver o artigo de Ramón Fernandez (1996), assim como a resposta de Paulani (2003, 2005).
} 
projeto totalizante e pretensamente unificador de Hegel, ainda se mantinha, de alguma forma, refém de um certo princípio da subjetividade. Neste sentido, se Paulani tivesse se preocupado em tentar compreender a obra de Habermas a partir do que ele mesmo se propunha, poderia ter sido levada a melhor compreender o porquê de Habermas ter se preocupado em demonstrar a importância da crítica do princípio da subjetividade moderna (tal como intentada inicialmente por Hegel). Assim como poderia melhor compreender como, também a partir da crítica de Hegel, Habermas se propõe, ele mesmo, a aprofundar sua crítica no sentido da construção de uma nova perspectiva filosófica com o intuito de substituir o princípio subjetivista da modernidade (ainda presente em Hegel e Marx) por uma teoria da ação comunicativa assentada em bases intersubjetivas e não em princípios de racionalidade estritamente subjetivistas e instrumentais.

A interpretação de Paulani acaba por lhe impor, a nosso ver, uma limitação que se manifesta ao enxergar Hegel apenas como filósofo da crítica da subjetividade que ajudou Marx a desvendar o princípio privatista, utilitarista e individualista da modernidade capitalista do século XIX (ver Paulani, 2005). A novidade da interpretação que Habermas faz de Hegel, ao contrário, nos parece ir muito além desta simples constatação de viés marxista. Se entrarmos no debate mais completo sobre o projeto filosófico de Habermas, cremos que podemos compreender bem melhor o sentido mais profundo de algumas colocações autocríticas que Habermas desfere contra a tradição subjetivista da modernidade. Autocrítica esta que, segundo o mesmo, só poderia se completar — de modo a manter até o limite os elementos críticos, auto-referentes e emancipatórios do projeto filosófico da modernidade - , se fossemos capazes de superar definitivamente também os resquícios dos fundamentos subjetivistas ainda presentes nas perspectivas filosóficas; tanto de tradição hegeliana, como marxista.

Superação esta, portanto, que só poderia se concretizar a partir do momento em que a tradição da modernidade se tornasse capaz de afirmar definitivamente novos princípios de racionalidade que nos permitisse ir além dos princípios da filosofia do sujeito. E que, por esse caminho, fossemos capazes de adentrar por meio de uma concepção de racionalidade verdadeiramente emancipatória, que desse vazão a uma ampliação do conceito de racionalidade instrumental (tal como compreendida inicialmente por Weber), abarcando de forma definitiva a noção de racionalidade comunicativa (intersubjetiva). Empreitada esta que, de acordo com o próprio Habermas, nem Hegel nem Marx conseguiram efetivamente concretizar.

\section{A VIRADA LINGÜÍSTICA DA FILOSOFIA CONTEMPORÂNEA E OS LIMITES FILOSÓFICOS DA INTERPRETAÇÃO ANTI-RETORICISTA DE PAULANI}

O texto "Retórica e Neoliberalismo: o capítulo brasileiro", de Paulani, é também um bom exemplo da insuficiência filosófica atual de críticas anti-retoricistas 
que buscam, ainda hoje - mais de meio século após a ocorrência da chamada virada lingüística na filosofia contemporânea - se fundamentar (mesmo que aparentemente sem ter consciência disso) em princípios transcendentais subjetivistas que desconsideram o papel da linguagem na constituição do significado dos conceitos teóricos e empíricos (sejam eles científicos ou filosóficos). Esta deficiência filosófica se torna explícita na medida em que a autora busca através da própria constituição do conceito hegeliano de consciência absoluta, via Marx, constituir seu argumento filosófico com o intuito de construir uma crítica da abordagem retórica em economia. Uma crítica que se assenta ainda na idéia de totalidade enquanto locus de caráter subjetivista, supostamente capaz de reconstruir teoricamente e melhor reorientar o discurso filosófico da modernidade rumo a uma autofundamentação da consciência de si, tal como proposta inicialmente por Hegel.

É neste sentido que podemos afirmar que Paulani - mesmo baseada em uma tradição filosófica marxista supostamente materialista e não idealista (como Hegel) - ainda não conseguiu (do ponto de vista filosófico) se desvencilhar completamente das limitações da tradição subjetivista da modernidade. Esta dificuldade, a nosso ver, se explica tendo em vista que a crítica de Paulani sobre o princípio da subjetividade moderna - tal como presente também em seu livro Modernidade e Discurso Econômico - se assenta única e exclusivamente sobre uma perspectiva filosófica que se limita a considerar as críticas hegelianas ao individualismo iluminista, assim como aos limites da filosofia transcendental de Kant, ${ }^{2}$ sem levar em consideração autores como Niezsche, Heidegger, Wittgenstein, Apel, Habermas, Rorty etc... Autores considerados fundamentais para a compreensão de qualquer debate dentro do campo da filosofia crítica da linguagem contemporânea.

Neste sentido, para nós, Paulani parece não conseguir se desvencilhar completamente da pretensão subjetivista hegeliana e marxista de tentar construir um sistema filosófico completo, racionalmente concebido, e comprometido com o projeto de reconstituição da idéia de totalidade histórica. Paulani continua, portanto, preza ao ideal da consciência absoluta de Hegel. Mesmo que em seu texto ela se esforce por demonstrar as limitações da filosofia de Hegel a partir de uma leitura marxista, que relembra argumentos anti-idealistas a favor de uma suposta práxis revolucionária materialista (tal como presentes originalmente na Ideologia Alemã de Marx).

Paulani, a nosso ver, foge do debate lingüístico proposto por McCloskey, fazendo uma crítica externa, pouco comprometida com o avanço interno da pers-

\footnotetext{
${ }^{2}$ Filosofia esta compreendida por Hegel como sendo uma perspectiva filosófica que se limitava à reflexão sobre a nossa capacidade fenomenológica e aparente de entendimento do mundo; não se preocupando com o desvendar da realidade racional (real) que, segundo Hegel, só poderia se desvelar a partir de uma autêntica investigação filosófica que se preocupasse em ir além da perspectiva do entendimento, e que fosse capaz de apreender dialeticamente o real a partir do pressuposto da constituição da totalidade histórica ou do espírito absoluto.
} 
pectiva retórica em economia. Uma perspectiva que pouco parece se interessar, inclusive, em tentar responder as críticas anti-hegelianas e marxistas feitas a partir da ótica da filosofia da linguagem por autores como Habermas, Rorty, Gadamer, entre outros. Críticas estas que, de certa forma, atingem impreterivelmente a própria perspectiva filosófica materialista que Paulani procura se utilizar com o objetivo de contestar a perspectiva retórica de McCloskey.

O debate sobre os limites do subjetivismo moderno e das abordagens totalizantes de Hegel e Marx, assim como a tentativa contemporânea de sua superação a partir da perspectiva da virada lingüística, portanto, pretende nos mostrar as limitações de críticas como as de Paulani, que em nome da Verdade e de uma perspectiva supostamente crítica, não conseguem avaliar e perceber os limites de seus próprios fundamentos subjetivistas e metafísicos. A análise de Paulani é problemática do ponto de vista filosófico, a nosso ver, portanto, porque se baseia em uma perspectiva materialista-subjetivista que não reflete hermenêuticamente sobre sua própria condição histórica. O que para nós representa uma espécie de contradição conceitual a qual algumas tradições marxistas ainda hoje insistem em desconsiderar. A crítica a este tipo de estratégia materialista é uma crítica que já havia sido feita por autores da antiga Escola de Frankfurt, e que se prolongam até os dias de hoje, com os trabalhos mais recentes sobre a hermenêutica em Gadamer, Habermas e Ricoeur; sem contar com as posições de filósofos neopragmatistas como Richard Rorty.

No entanto, na prática, ainda continuam a ser ignorados por alguns autores de tradição marxista. Ou seja, autores que continuam a reforçar argumentos a favor de uma espécie de historicismo que não consegue perceber que a crítica ao neoliberalismo (por exemplo) em tempos atuais, não pode ser feita de forma coerente e filosoficamente sofisticada pressupondo a materialidade histórica apenas das construções teóricas tidas como adversárias (neoliberais) ao mesmo tempo em que concebe a si mesmo como resultado de alguma perspectiva absoluta e não histórica pela qual se tenta conceber a realidade por um prisma nitidamente privilegiado do ponto de vista racional. Este tipo de perspectiva, portanto, seria do ponto de vista filosófico, como uma espécie de crítica materialista que ainda não conseguiu se desvencilhar completamente da metafísica idealista a qual o próprio materialismo de tradição marxista originalmente tentou se contrapor. Este foi um dos pontos fundamentais que levaram Adorno e Horkheimer, por exemplo, a fazerem uma autocrítica do marxismo e da tradição materialista na década de 30 e 40. Perspectiva esta que os levou a buscar uma nova perspectiva filosófica com o objetivo de construir uma autêntica filosofia crítica. Uma filosofia que buscasse se dar conta criticamente das limitações lógicas e conceituais que um materialismo, verdadeiramente crítico, deveria se dar conta historicamente.

Neste sentido, desconsiderando mais de meio século de debates filosóficos sobre a linguagem e sobre a percepção contemporânea dos impasses do projeto filosófico da modernidade, o argumento de Paulani se passa como se nada disso tivesse acontecido. É como se ela pudesse ser capaz de observar a realidade mundial e brasileira por um prisma externo e privilegiado. E daí, ao mesmo tempo, 
pudesse dizer o que é ideologia e o que não é. Ao contrário do que pensa a autora, cremos que esta seja uma postura intelectual problemática, que inviabiliza uma reflexão realmente crítica e moderna. Para nós, este tipo de postura, no limite, acaba por nos manter presos a uma perspectiva epistemológica (ou ontológica) a qual não se permite conceber a si próprio como ideologia; e que, portanto, acaba impondo restrições filosóficas que limitam sua própria capacidade de auto-reflexão crítica. Este sempre foi um dos grandes problemas do positivismo; mas também parece ser o problema de algumas correntes marxistas que desconsideram o debate sobre a filosofia crítica da linguagem contemporânea.

O problema deste tipo de postura filosófica, a nosso ver, é que ela muitas vezes acaba por se afirmar como postura tão ou mais conservadora e contraditória do que o próprio positivismo. Pois apesar de admitir abstratamente, diferentemente deste último, o caráter ideológico do saber; não é capaz, por sua vez, de conseguir enxergar a metafísica historicista-materialista que está por trás de seu próprio pensamento. É cega, portanto, também, pois advoga a crítica de ideologia; mas, ao mesmo tempo, não é capaz de refletir sobre sua própria condição ideológica. Critica posições adversárias por serem ideológicas, pressupõem muitas vezes que toda forma de pensamento é ideológica, mas, ao mesmo tempo, se consideram fundamentalmente acima de qualquer ideologia.

Dessa forma, desconsideram a dimensão histórica (e lingüística) que limita sua própria capacidade de representar a si mesmo e ao mundo. Pensam como se suas convicções teóricas particulares tivessem sido formadas em algum fórum intelectual cosmológico onde um consenso seria o único resultado racionalmente esperado e dado para todos os participantes envolvidos e capazes de compreender racionalmente, e de forma privilegiada, a natureza do debate acadêmico em questão. Não como um consenso intersubjetivo e local (historicamente datado) que se forma a partir de situações concretas em condições históricas específicas, e que, portanto, não passam de acordos formados contingencialmente e voltados para as necessidades que nos são colocadas pela realidade; esta sim entendida num sentido materialista crítico e modernista.

\section{RETÓRICA E NEOLIBERALISMO: ALGUMAS CONSIDERAÇÕES FINAIS}

Tendo em vista estes comentários gerais, poderíamos afirmar que os propósitos do projeto retórico nos parece levar muito mais em consideração a crítica da ideologia e a "realidade" do capitalismo contemporâneo (inclusive a ideologia neoliberal e o cientificismo presente em argumentos metodológicos neoclássicos, etc...) do que posições críticas à perspectiva pragmática e retórica. A tradição da crítica de ideologia marxista seria muito melhor orientada filosoficamente se não fosse assumida e afirmada a partir de uma condição absoluta e totalizante que se pressupõe privilegiada; mas sim, ao contrário, como frutífera e perspicaz 
crítica pragmática, com seu significado histórico e político datado e limitado a esta condição finita que lhe é peculiar.

Paulani, no entanto, à revelia destes argumentos — assimilados de forma apressada e pouco esclarecedora como argumentos pós-modernos e, portanto, tidos como niilistas, relativistas, irracionalistas etc... - tenta atingir a abordagem retórica na economia com críticas que fogem das implicações de caráter pragmático e lingüístico com a qual a filosofia tem se construído contemporaneamente. Com críticas externas e supostos achados que buscam identificar o surgimento da retórica com o avanço do neoliberalismo, Paulani procura ideologizar o debate retórico como se este fosse nada mais nada menos, do que uma nova roupagem para a velha "ladainha" neoliberal que têm ultimamente se imposto politicamente na América Latina. Não percebe que suas críticas a esse mesmo neoliberalismo, da forma como são desferidas, acabam por reforçar e reproduzir politicamente este mesmo discurso à medida que simplifica sua análise e as separa de um certo "consenso" filosófico atual, transformando o debate acadêmico numa "queda de braço" incomensurável. Este sim, irracionalista por natureza, e de caráter explicitamente destrutivo do ponto de vista intelectual e crítico.

Neste sentido, podemos afirmar que a tentativa crítica anti-retoricista de Paulani não parece responder internamente e de forma satisfatória às questões filosóficas de origem hermenêutica e pragmática que colocam em cheque concepções absolutistas (sejam elas materialistas, idealistas, metafísicas etc...) que serviram historicamente como sustentáculo intelectual para posições de origem historicista e materialista. Seus argumentos, a nosso ver, passam longe de qualquer menção dialogal a este debate. A estratégia de cunho fundacionista de conceber a defesa aberta do debate teórico e argumentativo, entre as várias correntes econômicas, como algo completamente desprovido de qualquer significado crítico ou racional (Paulani 1996, 2003) é, a nosso ver, o resultado natural desta incompreensão da autora em relação aos elementos radicalmente inovadores que tanto o neopragmatismo de Rorty como a perspectiva hermenêutica de Habermas, por exemplo, procuram trazer para o debate filosófico e científico contemporâneo. É daí, portanto, que parece surgir, a nosso ver, a confessa postura avessa da autora em relação à perspectiva retórica de McCloskey.

No entanto, é importante deixar claro que Paulani também não está exatamente errada ao buscar em Marx uma primeira inspiração autêntica da crítica racionalista que supostamente poderia sustentar uma substituição da tradição idealista da modernidade tal como proposta por Hegel. O problema é que, ao fazer este tipo de corte filosófico que passa de Hegel a Marx, e daí tenta atingir a retórica de McCloskey - sem fazer a mediação necessária que leva Marx à escola de Frankfurt, dessa a Habermas e daí à virada lingüística e a Rorty — Paulani demonstra uma "fuga" que desconsidera o debate filosófico sobre a linguagem (a qual boa parte da tradição filosófica contemporânea se assenta). Busca criticar a abordagem retórica na economia utilizando como premissas argumentos filosóficos absolutistas os quais a própria abordagem retórica de McCloskey procura refutar em seus argumentos preliminares. 
Num movimento que desconsidera o contexto intelectual do debate filosófico ocorrido no seio da filosofia da linguagem na segunda metade do século XX, Paulani tenta forçar uma associação, no mínimo inusitada, entre retórica e neoliberalismo com o intuito (a nosso ver também retórico, é claro) de desmerecer e diminuir as abordagens retóricas perante sua platéia de economistas heterodoxos. Tenta identificar as posições retoricistas como posições que supostamente reforçariam as práticas neoliberais hoje existentes no meio político e econômico latino-americano; o que, ao mesmo tempo, as tornaria como que supostas ameaças tanto para a heterodoxia, como para qualquer pensamento que se pressuponha, na perspectiva da autora, "autenticamente crítico" em relação às práticas neoliberais.

Não acreditamos, entretanto, que posturas autenticamente críticas possam tentar se imunizar epistemologicamente de supostas críticas que venham no sentido de contestar seus fundamentos ontológicos ou conceituais. Uma perspectiva autenticamente crítica e intersubjetiva, para nós, deve necessariamente assumir algum grau de vulnerabilidade conceitual e lingüística que as permita transformar-se em perspectivas falíveis do ponto de vista pragmático. É neste sentido que as abordagens metodológicas pragmatistas e hermenêuticas demonstram seu valor em contraposição a abordagens fundacionistas; sejam elas de matriz marxista ou positivista.

A abordagem retórica nos impele a considerar a crítica como condição natural da prática do discurso científico, limitando a capacidade filosófica das teorias de se pressuporem possuidoras de uma carga ontológica ou epistemológica que as tornem imunes de serem contestadas crítica e epistemologicamente. A nosso ver, é também com o objetivo de fazer coro a este debate filosófico amplo que Habermas pretende superar a tradição subjetivista da modernidade (à qual Hegel e Marx ainda se mantém presos do ponto de vista filosófico), a partir de uma perspectiva filosófica original que busca melhor valorizar a dimensão intersubjetiva no resgate das pretensões de validade (verdade, correção e veracidade). Uma perspectiva filosófica ainda moderna que busca resgatar os primórdios da tradição da modernidade e seu ideal da busca pela autonomia e da comunicação ideal contra as mais variadas formas de dominação e imunização ainda presentes nas perspectivas subjetivistas da modernidade do século XX.

Saindo em defesa ao "projeto retórico", portanto, não acreditamos que faça qualquer sentido afirmar que a retórica de McCloskey seja um caminho filosófico que impossibilite a crítica da ideologia; tornando-se uma espécie "ingênua", provedora de solo fértil para o desenvolvimento do neoliberalismo. Ao contrário, cremos que seu objetivo é exatamente nos permitir fazer esta crítica sem contradições internas e assumindo a impossibilidade de se fazer qualquer tipo de crítica a partir de perspectivas que se pressupõem privilegiadas Uma perspectiva que nos permita, inclusive, nos manter no seio de uma tradição filosófica crítica que, da mesma forma que Marx, nos dê subsídios para afirmar, sem contradições internas, que "tudo que é sólido desmancha no ar". 


\section{REFERÊNCIA BIBLIOGRÁFICAS}

Aldrighi, Dante e Salviano Jr., Cleofas (1996) “A grande arte: a retórica para McCloskey”. In: Rego (1996).

Anuatti Neto, F. (2003) "Persuasão racional: uma análise do esforço de Keynes na formação de uma opinião favorável à mudança nas políticas econômicas". In: Gala e Rego (2003).

Arantes, Paulo E. (1996) Ressentimento da dialética: dialética e experiência intelectual em Hegel. São Paulo: Paz e Terra.

Bianchi, Ana M. (2003) "Para auditórios diferentes, diferentes argumentos: retórica econômica nos primórdios da escola latino-americana". In: Gala e Rego (2003).

Fernández, Ramón G. (1996) “A retórica e a procura da verdade em economia”. In: Rego (1996).

Fernández, Ramón G. e Pessali, Huascar F. (2003) "Oliver Williamson e a construção retórica da economia dos custos de transação". In: Gala e Rego (2003).

Gala, Paulo (2003) “A retórica na economia Institucional de Douglas North”. In: Gala e Rego (2003).

Gala, Paulo e Rego, José M. (2003) A História do Pensamento Econômico como Teoria e Retórica: Ensaios sobre Metodologia em Economia. São Paulo: Editora 34.

Habermas, Jürgen ([1968] 1997). "Trabalho e interação: notas sobre a filosofia do espírito de Hegel em Iena”. In: Habermas, J. Técnica e ciência como “ideologia”. Lisboa: Edições 70. - ([1981] 1999) Teoría de la Acción Comunicativa (2 vols.). Madri: Taurus. . ([1983] 1989). Consciência Moral e Agir Comunicativo. Rio de Janeiro: Tempo Brasileiro. . ([1985] 2000). O Discurso Filosófico da Modernidade. São Paulo: Martins Fontes.

Paulani, Leda. "Idéias sem lugar: sobre a retórica da economia de McCloskey". In: Rego (1996). . (2003) "Modernidade e discurso econômico: ainda sobre McCloskey". In: Gala e Rego (2003). - (2004) "Retórica e neoliberalismo: o capítulo brasileiro". Anais do XXXII Congresso Nacional de Economia . João Pessoa: ANPEC. Disponível em: http://www.anpec.org.br/encontro 2004.htm . (2005) Modernidade e discurso econômico. São Paulo: Boitempo.

Rego, José M. (1996) “Retórica na economia - Idéias no lugar”. In: Rego (org.), Retórica na Economia. São Paulo: Editora 34.

Rorty, Richard ([1998] 2005) Verdade e Progresso. São Paulo: Manole. Originalmente publicado em inglês pela Cambridge University Press 1998.

Schwarz, Roberto ([1977] 2003) "As idéias fora do lugar". In: Ao vencedor as batatas: forma literária e processo social nos inícios do romance brasileiro. São Paulo: Editora 34. 